\title{
Implementation of Internet of Public Fitness Equipment for Health Physical Fitness Improvement
}

\author{
CHING-TING HSU ${ }^{1}$, YANG-HUNG CHANG ${ }^{1}$, JEN-SHI CHEN $^{1}$, WEI-HUA HO ${ }^{1}$, \\ HAU-HAN LIN ${ }^{2}$ AND JO-YIN CHOU ${ }^{3}$ \\ ${ }^{1}$ Graduate Institute of Sports Equipment Technology, \\ ${ }^{2}$ Graduate Institute of Sport, Leisure and Hospitality Management, \\ ${ }^{3}$ Urban Industrial Management and Marketing \\ ${ }^{1,3}$ University of Taipei, \\ ${ }^{2}$ National Taiwan Normal University \\ No. 1, Sec. 2, ChungCheng Rd., Shihlin Dist., Taipei City. \\ TAIWAN, R.O.C. \\ jingting@utaipei.edu.tw
}

\begin{abstract}
In this paper, an IoT architecture for public fitness equipment, internet of public fitness equipment, with software and hardware is propo sed and implemented. We utilize reed switch and MCU with WiFi module to implement IoT hardware on public fitness equipment. Furthermore, we also implement web service, database and user inte rface which provide thorough individual exercise prescription and monitor service. From the experimental results, all the participants' physical fitness does improve significantly. It shows that our internet of public fitness equipment can significantly improve body health by providing an efficient exercise way.
\end{abstract}

Key-Words: - Internet of Things, Public fitness equipment, Health related physical fitness

Received: October 9, 2019. Revised: January 24, 2020. Accepted: February 10, 2020.

Published: February 24, 2020.

\section{Introduction}

In the nowadays society, less exercising easily leads us to obesity. There are more than one reasons wellknown by us generation, the changes of our lifestyle and the social structure, which appears to be sedentary lifestyle more than active lifesty le for most of the population currently. Wakabayashi et al. and Warburton et al. denote that obesity is associated to chronic diseases, such as hypertension and type 2 diabetes, are all indicate d with Body Mass Index. Which is why, workout a nd periodic inspection are crucial $t$ o preventing diseases, according to the World Health Organiz ation [1][2]. Hence, enhancing lifest yle by improving their regular exercise and promoting the consciousness of health self-management for all the comm unities as well as prospering the hea lth industry have become the priorities all over the world. Mor e and $\mathrm{m}$ ore gyms and act ivity centers located, proving that we human have new conc epts on workout and managing a healthy body. Furtherm ore, from the Cohen et al., having $\mathrm{m}$ ore fitness equipment at public spaces really do attract more users and have a huge effect on local exercising [ 3]. As the analysis of Taipei Departm ent of Sports, 73. 4\% of the respondents over 15 years old are the most usual users using community park and school facilities; as for the elders over 60 , reaching still $74.89 \%$ respondents make good use of public activity spaces
[4]. From the data $\mathrm{m}$ entioned, we are $\mathrm{m}$ ore convinced of increasing public fit ness equipment motivates the participation among residents and will benefit their mental and physical health.

Literally, public fitness equipment is the exercising facilities in public places. The equipment such as Air Walker or tools providing workout functions are all the ones referred. They have all in common of having sim ple structure and fu nctions for us to understand easil y. Meanwhile, even from the analyses show that, the in-house professional fitness equipment as $\mathrm{w}$ ell as the public fitness equipment affect similarly on workout. By using public fitness equipment, we can improve health related physical fitness [5]. The gre atest advantage of expanding public fitness equipment in the neighborhood is providing the facilities to the public. Regardless to the $\mathrm{f}$ act, the large am ount of equipment will cause problem $\mathrm{s}$ when faci $\mathrm{ng}$ maintenance. Yet, com paring to the in-house gy $\mathrm{m}$ which contains professions and the appropriate instruction provided, the public fitness equipm ent will bring non-effect to body or even worse, sport injury, if w e didn't notice the cond ition of the equipment or understand well of the guide without professional leading. With the rapid development of the technology, not only the basic construction $b$ ut microprocessor will support when realizing the IoT device idea. The intention of this resear ch is to 
conduct on IoT device with microprocessor and WiFi module, offering users the exercise prescription and keep the $\mathrm{m}$ updated with the IoT device which named internet of public fitness equipment proposed in this resear ch. The final purpose is t o take advantage of the device to improve health related physical fitness of the public.

The rest of this paper is as follows. Next Section, we will discuss some rel evant works. Section III describes us implemented internet of public fitness equipment and how the exercise pr escription for health related physical fitness works. Section IV and $\mathrm{V}$ show our experimental results and conclusion, respectively.

\section{Review of Relevant Works}

In this section, we are going to discuss the effect of public fitness equipm ent and related re searches of health care com bining IoT. Warb urton et al. indicates that with regular exercising. The authors denote that regular exercising can effectively prevent chronic diseas es of all age $\mathrm{s}$ and extend human lifespan [6]. These features allow us to admit that public fitness equipme nt plays a crucial role in supporting our society and bring public health to our lives. Nguyen et al. takes the public fitness equipment from neighbor park as sedentary Hispanic women exercising tools. After experimenting for 6 weeks, Nguy en et al. saw significant effect on losing weight of respondents

[7]. Additionally, Wang et al. analyzes the usefulness of public fitness equip ment from the aspect of sports biom echanics [8]. In this researc $h$ which compares the gait of air walker, elliptical trainer and treadmill, we can discover that air walker and in-house trainer have the exercise intensity in common, users may obtain the sam e effect for th emselves. Lok et al. sorts out the characteristics of public fitness equipment fro $m$ many associated researches. They say that most of the researches do consider public fitness equipment benefit to public health. Apart from that, pubic fitness equipment in co mmunities have so me more characteristics such a s "social connectedness", "affordable", "support", and "d esign and promotion" [9]. Santamara et al. use Arduino as the core, surrounding by Bluetooth co mmunication interface to implement the wearable IoT device [10]. Via message queuing tele metry transport (MQTT), recording and exam ining users' condition and abnormal behavior during exercise, which will be uploaded to the cloud database, enables us to improve the disadvantages of inaccurate and noninstant from traditional record methods.

From the literature reviews above, it is obvious that public fitness equipment and in-house fitness equipment have lots in common. The two shows remarkable effect on keeping good health and exercise behavior, the y can even of fer adequate social support; yet, without the defect of can't record and analyze immediately. Thanks to the open source and thorou gh network infrastructure nowadays, we can practice IoTh ardware and software through open source and send/monitor the exercise prescription to our users. N amely, reaching the goals of regular exercise by using internet of public fitness equipm ents. In the next section, we are going to illustrate the internet of public fitness equipment architecture, the methods using Arduino to realize internet of public fitness equipment, and the design of pilot study.

\section{Proposed Internet of Public Fitness Equipment}

In this section, we will introduce hardware, software and user interfac e architecture of o ur proposed internet of public fitness equipm ent, and further introduce the design of this pilot study.

\subsection{Hardware and software design}

Fig. 1 show $\mathrm{s}$ the architecture of our prop osed internet of public fitness equipment. In this paper, we select Air Walker as our im plementation public fitness equipment which is one of the most popular equipment in parks. We take reed swi tches as the position sensor m onitoring user's gait on the Air Walker and use reed switches to c alculate users' step length and step frequency each time then s end the exercise processes t o database. Accordingly, hardware structure should contain enough General purpose input/output interface as well as the one with external communication. 


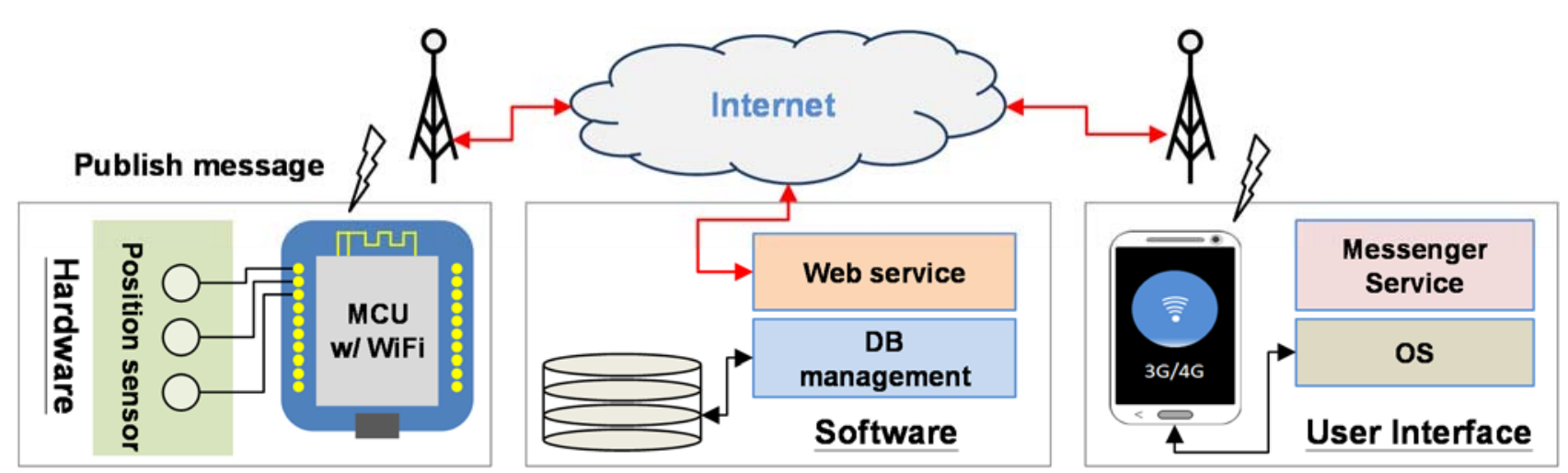

Fig. 1 Architecture of hardware, software and user interface

In this paper, we choose the device - D1 mini, based on ESP8266 and is able to open up Microcontorller unit by using Arduino. This is a low power consumption 8-bits MCU. Its characteristic is that the co mmunication interface has already been built-in Wifi. We can upload users' exercise processes from public fitness equip ment to cloud through the well-built Wifi infrastructure. Also, due to that ESP8266 has standard Wifi int erface inside, we can practice the HTML packet directly. Shortly, exercise processes will be delivered by the methods of HTML for m. The greatest advantage is that by using TCP to deliver HTML, we can provide the communication of higher quality.

Software block handles sending and restoring of information. We built a web service inside the software, PHP, in our server for public fitness equipment to read exer cise processes delivered through the internet HTML package over the web service and store the $\mathrm{m}$ into database. In the meantime, software interface offers the API (application interface) to s end messages, in order to communicate with user interface.

User interface block represe nts the communication, which means delivering exercise processes and sport exercise fro $\mathrm{m}$ their personal trainer to user. In order to solve the problem of heterogeneity OS, we use chatting soft ware to build up chatbox. Exercise prescription designed by personal trainer and user' $s$ exercise process es are both sent on communication software. In this paper, we install $u$ ser interface into Line - the most frequently used application in Taiwan nowadays.

\subsection{Pilot study}

The exercise prescription for user given by fitness coach and observe the effect. We choose Air Walker as our public fitness equipment training example (as can be seen in Fig. 2). And install three magnetic switch sensors on air walk to calculate the usage time and frequenc y as our exercise history. The procedure of the system is showed on Fig. 3. In the pilot study, we recruit some participants, and named them userA, userB and userC . Besides, we recruit one private coach with R.O.C health fitness instructor level-2 license as a particip ant. Private coach is responsible for designing the exercise prescription applied on public fitness equipm ent for each user individually.

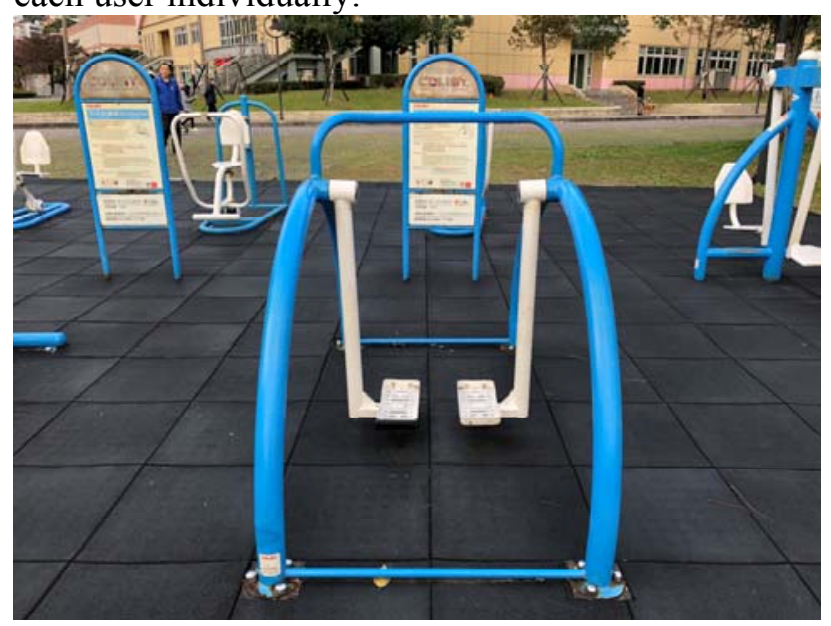

Fig. 2 Air walker

It is important that exercise prescription designed by the private coach is de livered via internet to the software square in Fig. 1. Software not onl y stores the exercise prescription in database $b$ ut do send through chatting software, Line messenger API to the system users. Fig. 4 is the Line scre enshot from the end-user. After recei ving exercise prescription, user starts to work on their exercise prescription in the fixed period. Exercise histor y will be sent to software square over the internet of public fitness equipment we proposed. 


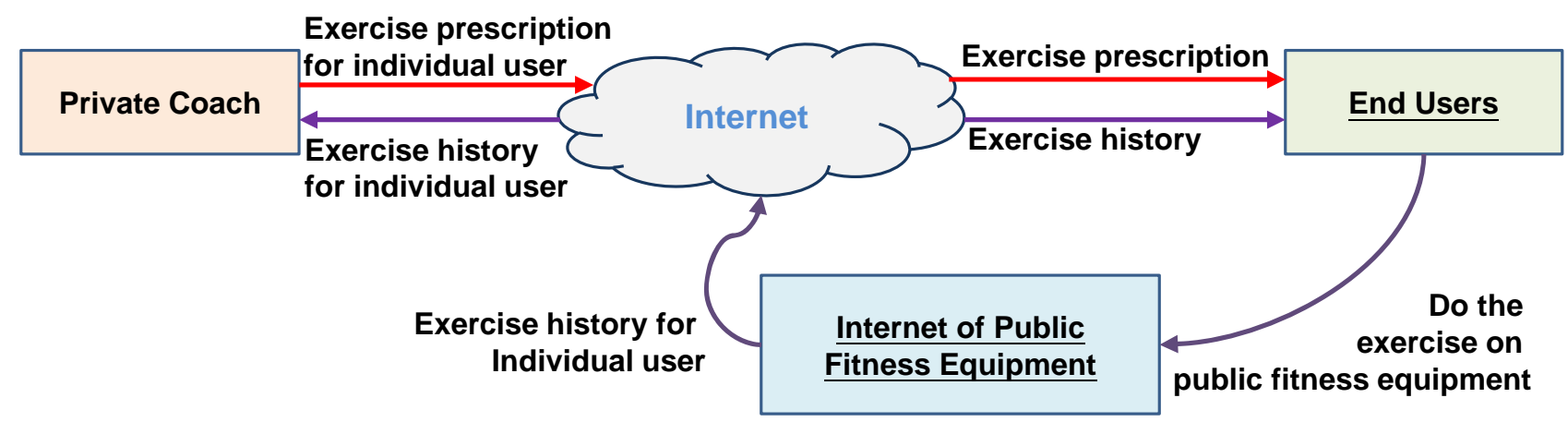

Fig. 3 Proposed system procedure

In the exercise process we delivered to user, in addition to the basic infor mation of public fitness equipment, the sy stem has done calculation of calorie consumption as well, providing the reference for private $\mathrm{c}$ oach and us er. As Fig. 5 shows that private coach can recei ve three users exer cise history on his mobile phone.

Private coach will also adjust the exercise prescription according to the processe $\mathrm{s}$ afterwards, offering the most instant and effective exercise prescription for users.

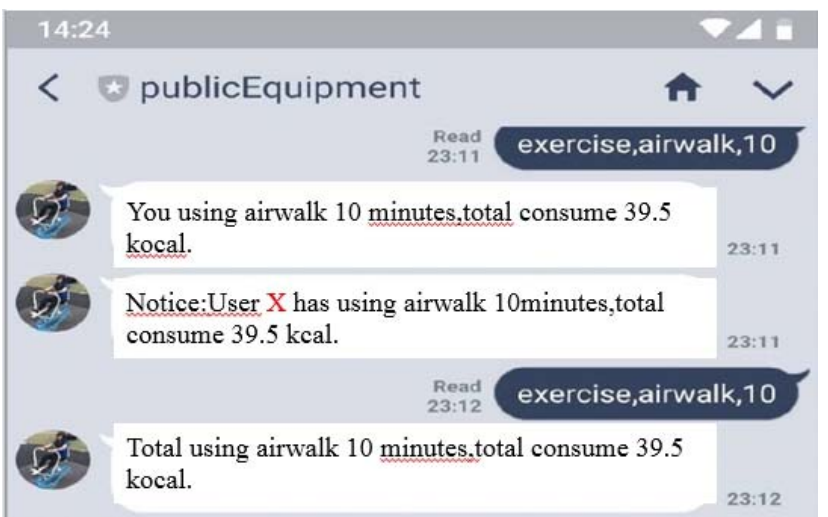

Fig. 4 End-user's interface - The exercise prescription and exercise history
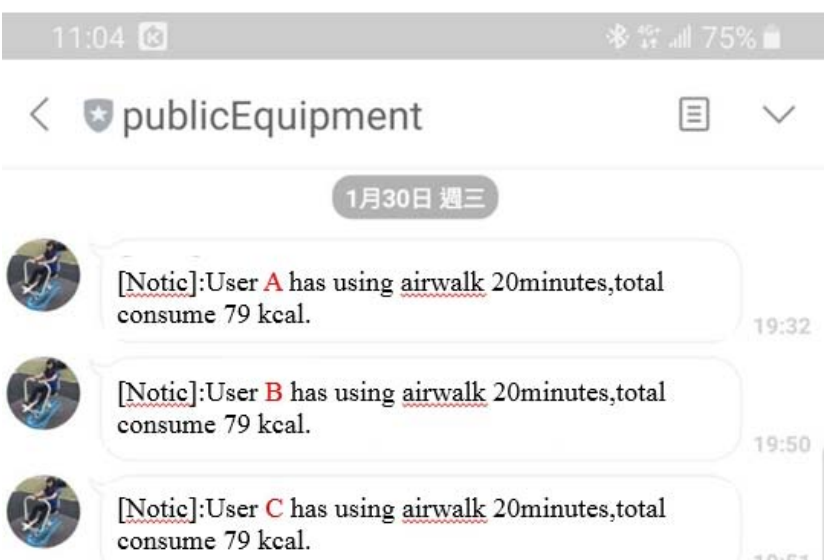
[Notic]:User A has using airwalk 20minutes,total
consume $79 \mathrm{kcal}$.

[Notic]:User B has using airwalk 20minutes,total consume $79 \mathrm{kcal}$.

[Notic]:User C has using airwalk 20minutes, total consume $79 \mathrm{kcal}$.

Fig. 5 Private's interface - End user's exercise history

\section{Experimental Results}

In this section, we show the experimental result of our pilot stu dy. We recruited 3 parti cipants whos age are be tween 24-27, female. They fully understand the risk of our experim ents and the right of participant, especially the $y$ can quit $t$ he experiment anytime without an y considering. The duration of the pilot study is from January 28th, 2019 to March 28, 2 019, totally $60 \mathrm{da}$ ys. Participants had a pre-test, day-20 test and post-test. Testing items are standing broad jump, 1 minute situps, the sit and reach test and $800 \mathrm{~m}$ jogging, they are tested for power, muscular endurance, flexibility and cardiovascular fitness, respectively. From these experimental results, we can obtain the effici ent of our proposed internet of public fitness equipment.

In the power test (s ee Fig. 6), the power of participant $\mathrm{A}$ on the twentieth day slightly increases but decreases on the sixtieth day, the value was even lower than the first day. The power of participant B has no improvement on the twentieth day, but then a slight increase on the sixtieth da y. Participant $C$ turns out to be the one increases noticeably. We can see that on both twentieth and sixtieth day, there're obvious increases.

Fig. 7 shows the experime ntal result of muscular endurance test. From this figure, we can obtain that participant A has no i mprovement, and little improvement for participant $\mathrm{B}$ and $\mathrm{C}$ compare to the first test on the twentieth day. On the sixtieth day, post-test, there're noticeable im provement for all. We can tell that subject $\mathrm{C}$ has the $\mathrm{m}$ ost noticeable increase on $\mathrm{m}$ uscular endurance. In the flexibili ty test (see Fig. 8), we can see that participant A and B improve less than $\mathrm{C}$ on the twentieth day. Then on the sixtieth day, they do have so me improvement compare to the first test. Participant $\mathrm{C}$ increases the most. 


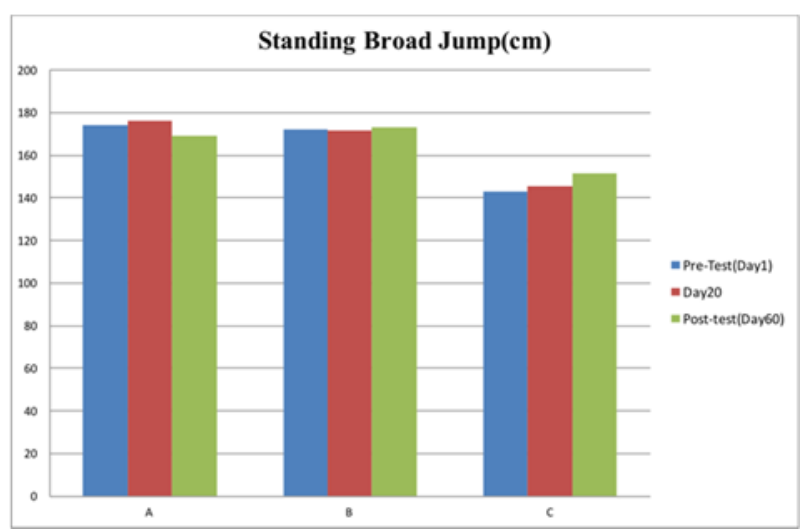

Fig. 6 Experimental results of standing broad jump (cm)

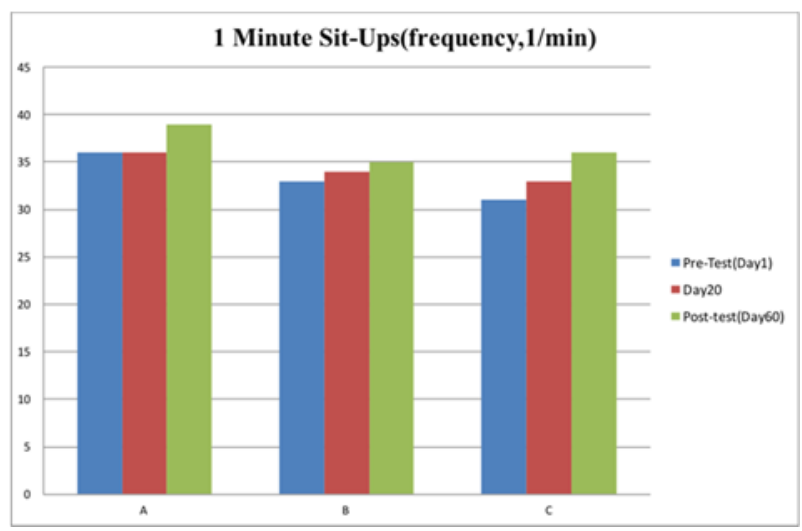

Fig. 7 Experimental results of 1-minute sit-up(1/min)

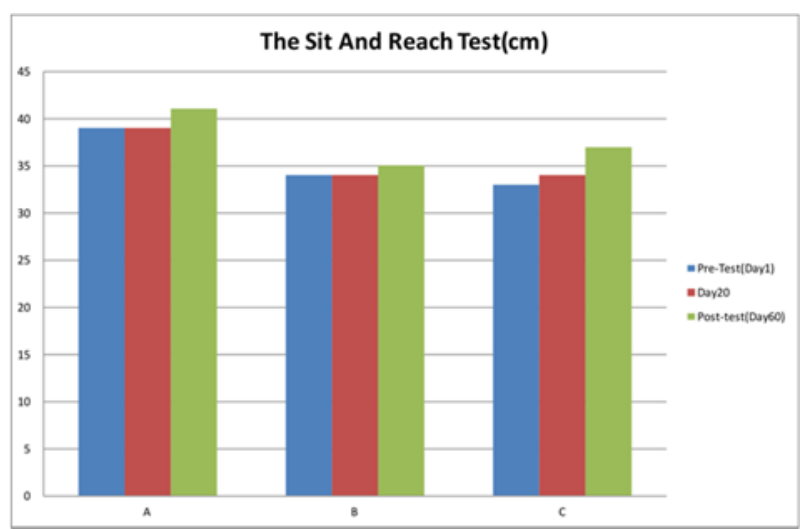

Fig. 8 Experimental results of the sit-and-reach test $(\mathrm{cm})$

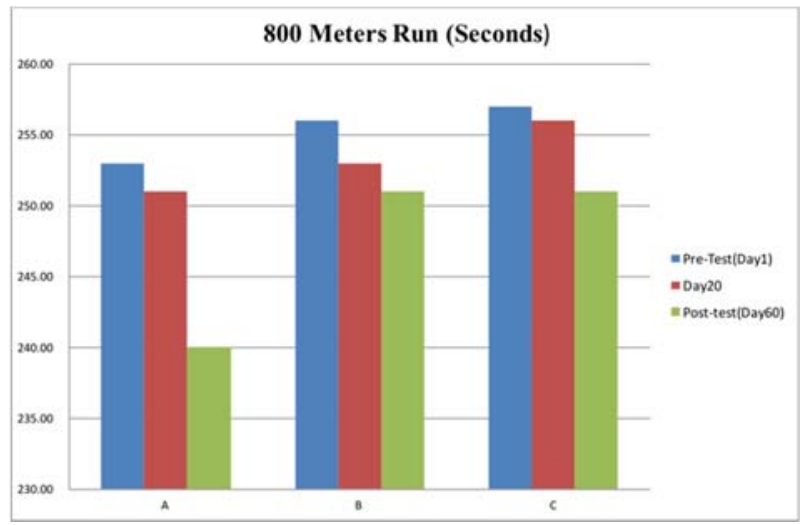

Fig. 9 Experimental results of 800 meters jogging (sec.)
Finally, we show the experimental result of cardiovascular fitness test which shown in Fig. 9. All our participants, A, B and C, do $\mathrm{m}$ ake significant improvement on both $t$ wentieth and sixtieth day, compare to the first test. Among them, A increases the most dramatically.

From these figures, we can obtain that, on the sixtieth day, participants show great improvement on all test, only participant A has a d ecrease in the power test. Among all the participants, A shows greatest improvement during the cardiovascular fitness test, the most noticeable incr ease for $\mathrm{C}$ on power and muscular endurance test. Co mpared with $\mathrm{A}$ and $\mathrm{C}, \mathrm{B}$ has the slig htest improvement on all tests. The only exercise prescription given is the exercise time, instead of the stepping frequenc $y$, may be the factor influences our experi mental results.

\section{Conclusion}

In this paper, we proposed and im plemented an internet of public fitness equipm ent which connects public fitness equipment with each other. Instructor sends exercise prescription re motely to user over IoT. Apparently, the result shows that for wo men with irregular exercise habit, their flexibility, power, muscular endurance, and cardiovascular fitness increase dramatically based on the value. After receiving the exercise history, the private coach can give personal exerci se prescriptions any time, anywhere. The private coach has no limited to the environment. Owing to that our internet of public fitness equipment and Air Walk have no intensity to adjust, designing exercis e prescription integrating with other sports is nece ssary to achieve effe ctive training performances. From this paper, not only government can $\mathrm{m}$ anage the $\mathrm{p}$ ublic fitness equipment easily, but also for citizens who ca $n$ utilize our proposed internet of public fitness equipment to improve their health physical fitness.

\section{Acknowledgement}

This research is supported b y Ministry of Science and Technology, Taiwan, R.O.C. The project number is $107-2410-\mathrm{H}-845-026$.

\section{References:}

[1] Ichiro Wakabayashi, "Relationships of body mass index with blood pressure and serum cholesterol concentratio ns at different ages," Aging clinical and 
experimental research, vol. 16, no. 6, pp. 461-466, December 2004.

[2] Darren E.R. W arburton, Crystal W. Nicol and Shannon S.D. Bredin, "P rescribing exercise as preventive therapy," Canadian medical association journal, vol. 174, no. 7, pp. 961-974, March 2006.

[3] Deborah A. Cohen, Terry Marsh, Stephanie Williamon, Daniela Golinelli and Thomas L. McKenzie, "Im pact and costdefinitiveness of family fitness zones: A natural experiment in urban public parks," Health and place, vol. 18, no. 1, pp. 39-45, January 2012.

[4] Department of Sports, The Study of Taipei Citizens' Participation in Sports, December 2005.

[5] Chia-Yu Wang, Pao-Hung Chung, Chiang Liu and Tzu-Yao Tai, "Com parison of stride length during air walker, e lliptical trainer and treadmill exercise," Chinese journal of sports biomechanics, vol. 7, pp. 38-41, October 2012.

[6] Darren E.R. W arburton, Crystal Whitney Nicol and Shannon S.D. Bredin, "Prescribing exercise as preventiv e therapy," Canadian medical association journal, vol. 174, no. 7, pp 961-974, March 2006.

[7] Caroline H. Nguyen and Marcella A. Raney, "Exercise training with fitness zone equipment in sedentary hispanic women: A pilot study," Californian journal of health promotion, vol. 12 , no. 1 , pp. 83-87, January 2014.

[8] Chia-Yu Wang, Pao-Hung Chung, Chiang Liu and Tzu-Yao Tai, "Com parison of stride length during air walker, e lliptical trainer and treadmill exercise," Chinese journal of sports biomechanics, vol. 7, pp. 38-41, October 2012.

[9] Janet Lok Chun Lee, Temmy Lee Ting Lo and Rainbow Tin Hung Ho,

"Understanding outdoor gym $\mathrm{s}$ in public open spaces- A system atic review and integrative synthesis o f qualitative and quantitative evidence," International journal of environmental research and public health, vol. 15, no. 4, March 2018.
[10] Amilcare Francesco Santamara, Floriano De Rango, Abdon Serianni and Pierfrancesco Raimondo, "A real IoT device deployment for e-Health applications under lightweight communication protocols, activity classifier and edge data filtering," Computer communications, vol. 128 , pp. 60-73, Septermber 2018.

[11] Ching-Ting Hsu, W e-Hau Ho and Jen-Shi Chen, "High efficient weightlifting barbell tracking agorithm based on diamond serach strategy," Advances in intellignet systems and computing, vol. 831, pp. 252-262, July 2018.

[12] WeMOS website: https://www.wemos.cc/ 